\title{
AVALIAÇÃO DO AUTOCONCEITO EM CADEIRANTES PRATICANTES DE ESPORTE ADAPTADO
}

\author{
Mirella Bagdadi Sernaglia \\ Universidade Estadual de Campinas, Campinas, São Paulo, Brasil
}

\section{Edison Duarte}

Universidade Estadual de Campinas, Campinas, São Paulo, Brasil

\author{
Vanessa Helena Santana Dalla Déa
}

Universidade Federal de Goiás, Goiânia, Goiás, Brasil

\begin{abstract}
Resumo
Este estudo teve como objetivo avaliar o autoconceito, por meio de suas dimensões (somática, pessoal, social e éticomoral), de cadeirantes que praticam esporte adaptado. O instrumento utilizado foi a Escala Fatorial do Autoconceito (EFA), proposto por Tamayo (1981). Os dados foram coletados uma única vez, em 13 voluntários, com idade de 28,46 anos, com lesão medular, independente do sexo e que praticam esporte adaptado por no mínimo duas horas semanais, há pelo menos três meses. Os resultados mostraram o autoconceito global com um escore de 3.99. Conclui-se que a população estudada avalia seu autoconceito de forma negativa, comparado a estudos anteriores com outras populações.
\end{abstract}

Palavras-chave: Autoconceito - Pessoa com Deficiência Física - Lesão Medular Esporte Adaptado

\section{Introdução}

$\mathrm{O}$ autoconceito, segundo Santana (2003), é a forma como o indivíduo se avalia, e desta avaliação dependerá seu sucesso afetivo, social e cognitivo.

Ainda segundo a mesma autora, todos os nossos atos, nossas vitórias e derrotas, nossas características físicas e psíquicas, as vivências que temos perante a sociedade e muitos outros aspectos influenciam no conceito que temos de nós mesmos. Ele está relacionado a tudo aquilo que cerca o indivíduo: o que ele é, o que ele quer, o que ele tem, como os outros o enxergam e como ele enxerga os outros. O autoconceito é estável, alterando-se em fases da vida (infância, adolescência, vida adulta, velhice), ou em caso de algum acontecimento marcante.

Por exemplo, uma pessoa que sofre um trauma e adquire uma defi- 
ciência, devido à lesão na medula, passa por um processo de desconstrução física, social e psicológica, tendo que se adequar a sua nova situação. No caso da lesão medular, seja na paraplegia ou na tetraplegia, a pessoa com deficiência tem perda total ou parcial dos movimentos dos membros inferiores e/ou membros superiores. Essa condição é, na maioria das vezes, irreversível e o uso da cadeira de rodas nesses casos torna-se indispensável.

Assim, a pessoa que adquire uma deficiência física no decorrer de sua vida, além da necessidade de se ajustar às alterações físicas, também necessita restabelecer sua vida social e reestabelecer-se psicologicamente. $\mathrm{O}$ que garantirá o sucesso nessa reinserção é a forma como essa pessoa reconstrói seu autoconceito a partir dessas mudanças, adaptando-se e compreendendo sua nova situação. A cadeira de rodas torna-se uma extensão de seu corpo (MAYEDA, 2005) e, conviver com esse auxílio trará nova percepção sobre o mundo e sobre a forma de viver, o que implica em maior ou menor grau a mudança no autoconceito.

O esporte adaptado pode ser uma boa opção para essa população que busca nele, além dos benefícios físicos, uma interação social e conscientização que possibilite avanços positivos nos aspectos psicológicos. Winnick (2004, p. 6) caracteriza o esporte adaptado como sendo "o esporte modificado ou criado para suprir as necessidades especiais dos portadores de deficiência". O autor afirma que ele pode ser praticado em ambientes integrados, onde pessoas com deficiência interagem com pessoas sem deficiência, ou em ambientes segregados, nos quais a participação esportiva envolve apenas pessoas com deficiência.

Segundo Brazuna e Mauerberg-DeCastro (2001), o esporte adaptado envolve muito mais do que uma competição entre equipes, para o atleta o esporte significa competir contra si, contra sua deficiência, contra o preconceito e a favor da vida.

Santana (2003) coloca que as relações sociais e outras vivências como a satisfação e a insatisfação, presentes na vitória ou na derrota dentro dos esportes e atividades físicas em geral, irão fazer parte da avaliação que o indivíduo faz dele mesmo. $\mathrm{O}$ esporte permite que seus praticantes vivam não apenas intensas experiências físicas, mas, principalmente, experiências psicológicas que somente sua prática pode proporcionar.

A definição de alguns termos é muito importante quando se trata 
de deficiência. Para Santana (2009) apud Dalla Déa e Duarte (2009), em relação aos termos relacionados à deficiência, a utilização dos mesmos de forma inadequada implica o risco de reforçar e perpetuar a ideia de falsos conceitos. Uma terminologia adequada não carrega preconceitos, estigmas e estereótipos.

Assim, a mesma autora coloca que o uso da expressão "portador de deficiência" ou "pessoa portadora de deficiência" tornou-se bastante popular no Brasil no período de 1986 a 1996. Porém, estes termos passaram a ser questionados pelo próprio grupo de pessoas com deficiência. A argumentação é que eles não portam a deficiência, o que significa o mesmo que levar ou carregar consigo, como se ora portassem, ora não portassem. Na metade da década de 1990, entrou em uso no país a expressão "pessoas com deficiência", que permanece sendo a mais adequada.

Para a compreensão do significado da deficiência, bem como suas implicações, Manhães (2004) ressalta a importância das vivências familiares, sociais e culturais de cada um. É essa relação com o mundo que fará com que os indivíduos enxerguem a deficiência de forma diferenciada para cada situação e para cada pessoa envolvida.

As deficiências físicas podem ter origem congênita, ou serem adquiridas durante a vida. A deficiência física adquirida, segundo Duarte e Gorla (2009) apud Gorla, Campana e Oliveira (2009) pode ter origem traumática, sendo mais frequentes a lesão medular por trauma na coluna vertebral e as amputações. Segundo o Censo do Instituto Brasileiro de Geografia e Estatística (IBGE, 2000), 900 mil pessoas apresentam paralisia por lesão medular no Brasil, sendo que a faixa etária de maior incidência está entre 18 e 40 anos, com predomínio do sexo masculino (5:1), e tendo os traumas como a causa mais comum.

Acometida pela brusca transformação corporal, a pessoa com deficiência física adquirida precisa mudar a maneira como percebe o mundo e a si mesmo. Segundo Mayeda (2005), o corpo no início passa a ser motivo de repúdio, já que essa nova sensação faz com que por alguns instantes o corpo e a memória do corpo passado entrem em conflito.

Amiralian (1986) apud Campos, Avoglia e Custodio (2007) coloca que a representação mental é o básico na formação do autoconceito, porém, indivíduos com lesão medular encontram maiores dificuldades para desenvolvê-lo após o trauma físico. O primeiro motivo é a limitação do seu movimento corporal, que impede um maior conhecimento 
do seu próprio corpo; enquanto que o segundo motivo diz respeito às percepções de sua imagem refletida no espelho, que são frequentemente negadas.

Existem alguns mecanismos de defesa que ajustam o sujeito sobre suas incapacidades. Baseados na literatura, a negação, projeção, formação reativa e regressão (AMIRALIAN, 1986 apud CAMPOS, AVOGLIA e CUSTÓDIO, 2007); e a repressão, sublimação, identificação, racionalização, fuga na fantasia e compensação (NOVAES, 1975 apud CAMPOS, AVOGLIA e CUSTÓDIO, 2007), são os mecanismos utilizados constantemente por pessoas com deficiência adquirida.

$\mathrm{Na}$ autopercepção o indivíduo é simultaneamente sujeito percebido e sujeito que percebe, objeto de conhecimento e sujeito conhecedor. Assim, o autoconceito designa as funções perceptivas e ativas. Porém, a percepção de si mesmo também implica na participação das funções ativas para defender, conservar e desenvolver a autopercepção. Ou seja, a autopercepção implica sempre um mecanismo regulador. Portanto, temos que o self é o conceito de si mesmo, desenvolvido e conservado ativamente (TAMAYO, 1981).

O mesmo autor ainda afirma que o autoconceito é uma organização hierárquica e multidimensional, coerente e integrada, de um conjunto de percepções de si mesmo. O self possui um caráter adaptável que é regulado pelo dinamismo individual, pelas características de interação social e pelo contexto situacional, ou seja, ele se adapta às exigências e solicitações da sociedade, da cultura, e do meio-ambiente. Assim, o autor considera que "o self é eminentemente social".

O autoconceito é composto por várias dimensões: o self social, o self pessoal, o self somático e o self ético-moral. A seguir, será abordada cada uma das dimensões de acordo com Tamayo (1981).

O self social consiste na abertura do indivíduo para os outros, na procura de interação, no desejo de complementaridade de si e do outro, na necessidade de reconhecimento pelos outros. É dividido em duas subestruturas: a) receptividade social, que é formada pelas percepções da predisposição social, do relacionamento interpessoal, da abertura do indivíduo aos outros, e da sua capacidade de comunicação; b) atitude social, que compreende os padrões de reação do indivíduo em seu relacionamento com os outros.

O self pessoal é a maneira como o indivíduo se percebe como pessoa, nas características psicológicas a que se atribui. Também é dividi- 
do em duas subestruturas: a) segurança pessoal, que é formada pelas percepções e sentimentos de permanência e de confiança em si mesmo; b) autocontrole, que consiste na maneira como o indivíduo disciplina sua atividade, suas relações e sua interação com o mundo.

O self somático é o resultado de um corpo físico, das percepções diretas e indiretas que o indivíduo tem dele, e da maneira como seu corpo é percebido pelos outros. A aparência física e o estado físico são componentes fundamentais do dessa dimensão. A estruturação deste self e a maneira como os diferentes membros do corpo são integrados nesta imagem, dependem da valorização cultural e histórico-individual de cada um. Assim, o self somático é baseado no corpo vivido, e não necessariamente no corpo anatomofisiológico, ou corpo objetivo.

O self éticomoral fornece ao indivíduo uma imagem da sua dignidade moral, baseada na forma como ele é percebido pelos outros, que é interiorizada e integrada como parte da sua própria percepção. Consiste nas crenças do que é bom e do que é mal.

Tamayo et al. (2001) afirma que o conteúdo do autoconceito é determinado tanto pela situação social na qual se encontra o sujeito como pelos seus interesses, metas e motivações do momento. E ao mesmo tempo, segundo Zugliani, Motti e Castanho. (2007), o autoconceito determina a trajetória do indivíduo, pois a visão mais profunda que tem de si influencia todas as escolhas significativas e as decisões, determinando o tipo de vida que o mesmo cria para si.

Mussen et al. (1995) apud Santana (2003) ressalta a diferença entre autoestima e autoconceito: enquanto o primeiro envolve avaliação; o segundo é um conjunto de ideias sobre si próprio que é descrito e não envolve julgamento de valor. Ou seja, a autoestima é a avaliação que o indivíduo faz sobre o seu autoconceito.

\section{Métodos}

Participantes

A seleção da amostra foi do tipo intencional e voluntária, conforme a disponibilidade e interesse dos sujeitos em participar da pesquisa (THOMAS; NELSON, 2002).

Os voluntários foram recrutados nos Projetos de Extensão da Faculdade de Educação Física da Universidade Estadual de Campinas, onde são oferecidas algumas modalidades de esporte adaptado, com 
foco nos cadeirantes, como o handebol e o rúgbi em cadeira de rodas (HCR e RCR). Participaram desta pesquisa apenas pessoas com deficiência física adquirida, com lesão medular de origem traumática, diagnosticados como paraplégicos ou tetraplégicos.

Foram coletados os dados de 13 lesados medulares que fazem o uso da cadeira de rodas em seu dia a dia e que praticam esporte adaptado por, no mínimo, duas horas semanais, há pelo menos três meses. Tempo considerado suficiente, devido à experiência dos pesquisadores, para que o sujeito tenha um envolvimento assíduo com o esporte. Em relação ao tempo de prática, foi considerada a prática de outras modalidades que não o RCR e o HCR. Os sujeitos poderiam ser de ambos os sexos, porém era imprescindível que fossem maiores de 18 anos.

Para a análise dos resultados e exposição dos dados, os voluntários foram identificados por letras de A a M de modo aleatório, sem relação alguma com seus respectivos nomes.

Abaixo, no Quadro 1, foram caracterizados os indivíduos de acordo com a idade atual, idade em que adquiriram a lesão, tempo de lesão, tipo de deficiência e o tempo de prática esportiva. $\mathrm{O}$ tipo de deficiência de cada voluntário foi definido por ser uma informação de visível e de fácil entendimento para quem tem experiência na área, sem necessidade de questionamento.

\begin{tabular}{c|cccccc}
\hline Individuo & Idade & $\begin{array}{c}\text { Idade } \\
\text { que } \\
\text { Adquiriu } \\
\text { a Lesão }\end{array}$ & $\begin{array}{c}\text { Tempo de } \\
\text { Lesão }\end{array}$ & $\begin{array}{c}\text { Tipo de } \\
\text { Lesão }\end{array}$ & $\begin{array}{c}\text { Tempo de } \\
\text { Prática } \\
\text { Esportiva }\end{array}$ & Modalidade \\
\hline A & 21 & 17 & 4 anos & Paraplegia & 3 anos & HCR \\
B & 38 & 14 & 24 anos & Paraplegia & 20 anos & HCR \\
C & 29 & 27 & 2 anos & Paraplegia & 6 meses & HCR \\
D & 32 & 22 & 10 anos & Paraplegia & 6 meses & HCR \\
E & 33 & 26 & 7 anos & Paraplegia & 2 anos & HCR \\
F & 30 & 23 & 7 anos & Tetraplegia & 3 meses & RCR \\
G & 32 & 17 & 15 anos & Tetraplegia & 1 ano & RCR \\
H & 23 & 21 & 2 anos & Tetraplegia & 2 anos & RCR \\
I & 22 & 17 & 5 anos & Tetraplegia & 4 anos & RCR \\
J & 32 & 27 & 5 anos & Tetraplegia & 5 anos & RCR \\
K & 35 & 22 & 13 anos & Tetraplegia & 1 ano e 6 & RCR \\
L & 20 & 15 & 5 anos & Tetraplegia & 1 ano e 2 & RCR \\
M & 23 & 18 & 5 anos & Tetraplegia & 7 meses & RCR \\
\hline
\end{tabular}

Quadro 1: Caracterização dos Indivíduos 
Instrumento

O instrumento utilizado para a coleta de dados foi a Escala Fatorial do Autoconceito (EFA), proposto por Tamayo (1981). Além de questões adicionais referentes ao sexo, idade, tempo em que pratica esporte adaptado, quantidade de horas semanais que dedica ao mesmo, e com qual idade adquiriu a deficiência.

A EFA é composta por 83 itens, relacionados a atributos bipolares, agrupados em quatro dimensões. Duas dessas dimensões apresentam subestruturas, denominadas fatores, que são seis ao todo: self pessoal (autoconfiança e autocontrole); self social (atitude social e receptividade social); self ético-moral; e self somático.

Devido à aplicação de questionários piloto anterior à pesquisa, notou-se uma dificuldade na compreensão do instrumento original, assim, foi decidido adaptar a EFA para melhor entendimento do voluntário, sem modificar seu significado original. Os itens originalmente são escalonados pela numeração de 1 a 7 , da esquerda para a direita, contendo atributos bipolares em cada extremidade, por exemplo:

\begin{tabular}{|l|l|l|l|l|l|l|l|l|}
\hline VIOLENTO & 1 & 2 & 3 & 4 & 5 & 6 & 7 & PACIFICO \\
\hline
\end{tabular}

O número 1 indica que o sujeito é muito violento, o número 4 é um ponto neutro, e o número 7 indica que ele é muito pacífico.

Neste trabalho, utilizamos a seguinte escala, com o intuito de minimizar as dúvidas e erros:

\begin{tabular}{|l|l|l|l|l|l|l|l|l|}
\hline VIOLENTO & MU & ME & PO & 0 & PO & ME & MU & PACIFICO \\
\hline
\end{tabular}

Legenda: $\mathrm{MU}=$ muito; $\mathrm{ME}=$ médio; $\mathrm{PO}=$ pouco; 0 = neutro

É importante esclarecer que a adaptação feita no questionário não interferiu no resultado, já que os dados obtidos foram transformados em números de 1 a 7 , de acordo com o escalonamento original utilizando-se as variáveis apresentadas no artigo que valida o instrumento descritas nas informações iniciais do mesmo.

A validação da EFA foi realizada no estudo feito por Tamayo (1981), no qual o autor não apresenta escores ideais de referência para indicar autoconceito positivo ou negativo. $\mathrm{O}$ autor apenas cita que um escore elevado (máximo de 7) indica um autoconceito positivo, e um escore baixo (mínimo de 1) manifesta um autoconceito negativo. Assim, temos que o ponto neutro da escala é o escore 4 , escores numeri- 
camente inferiores a ele iremos considerar como negativos, e maiores positivos.

\section{Procedimentos}

O presente estudo é do tipo transversal com delineamento descritivo e abordagem quantitativa, visto que o instrumento foi aplicado uma única vez; partindo da análise dos componentes de um fenômeno em que o pesquisador encontra-se afastado do processo de coleta de dados, uma vez que os dados serão analisados por fórmulas estatísticas por meio da utilização de instrumentos objetivos (THOMAS; NELSON, 2002).

Os instrumentos de pesquisa foram aplicados sempre após os treinos para que os voluntários não interrompessem sua prática. Devido à dificuldade de todos estarem presente em um único dia, a dependência com o transporte coletivo agendado, que fazia com que muitos não tivessem tempo disponível para responder às questões naquele momento e a impossibilidade de alguns voluntários tetraplégicos em segurarem a caneta sem o adaptador para escrita, os dados foram coletados em diferentes dias, com um intervalo máximo de quatro semanas entre o primeiro e o último voluntário.

Foram lidos e esclarecidos todos os aspectos éticos e o objetivo da pesquisa antes que os voluntários assinassem o Termo de Consentimento Livre e Esclarecido. Após o consentimento, foram dadas todas as instruções para o preenchimento da EFA. Cada voluntário preencheu seu questionário individualmente, sem que tivessem acesso às respostas dos demais.

Esta pesquisa foi aprovada sem restrições pelo Comitê de Ética em Pesquisa/FCM/UNICAMP, em 23 de Junho de 2009, através do parecer $\mathrm{N}^{\circ} 548 / 2009$. Os dados foram coletados em agosto e setembro de 2009 .

Análise dos dados

A análise estatística foi realizada por meio da Análise de Variância (ANOVA) 2X2. Também foi feita uma análise do comportamento geral das médias dos indivíduos e dos fatores. Em todas as etapas da análise estatística, adotou-se o nível de significância de 5\%. O software utilizado para as análises dos dados foi o MINITAB 15. 
Resultados

Os resultados obtidos por meio da Análise de Variância mostram que a diferença entre os escores médios do autoconceito de cada indivíduo não é estatisticamente significativa. Os dados indicam o maior autoconceito para o indivíduo A (escore 4.45), enquanto o indivíduo C apresenta o menor autoconceito (escore 3.65). Assim, a amostra apresenta um caráter homogêneo, sem discrepâncias entre os indivíduos.

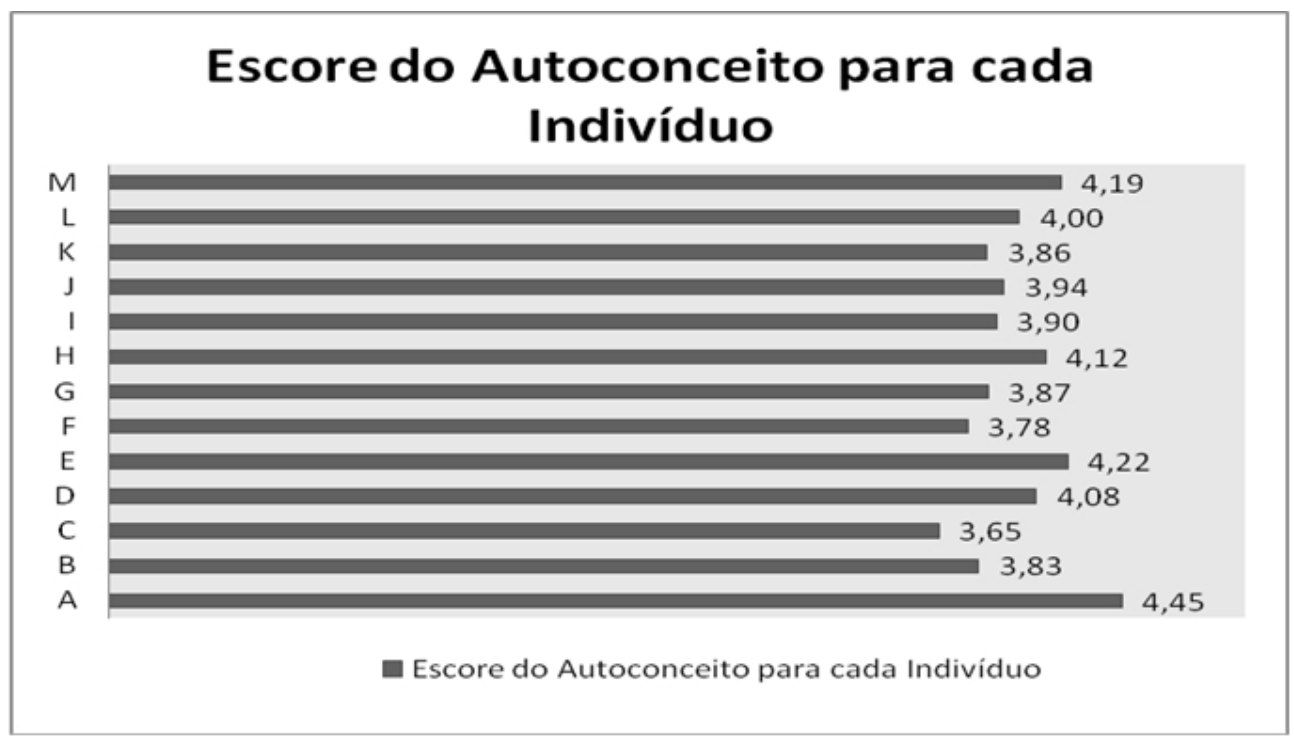

Figura 1: Escore do Autoconceito para cada Indivíduo

Já em relação aos fatores que compõem o autoconceito, os dados se mostram com diferenças estatisticamente significante ao nível de $5 \%$. O fator autoconfiança apresenta o maior escore médio (4.37), enquanto o fator atitude social apresenta o menor (escore 3.58).

\section{Escore para cada Fator do Autoconceito}

\section{Regras Sociais \\ Receptividade Social \\ Autocontrole \\ Autoconfiança \\ Atitude Social \\ Aparência Física}

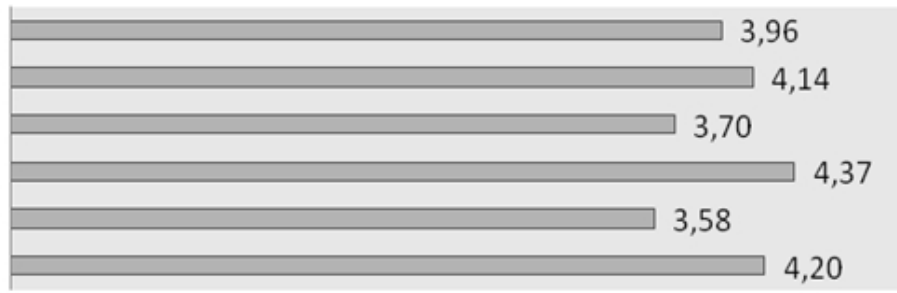

$\square$ Escore para cada Fator do Autoconceito

Figura 2: Escore para cada Fator do Autoconceito 
Devido à pequena amostra deste estudo, podem-se relacionar os resultados da ANOVA 2X2 com as médias parciais de cada indivíduo em relação aos fatores, e dessa forma verificar se a amostra se comportou de forma regular, com pequeno desvio padrão, ou se foi tendenciosa, com grande desvio padrão. A Tabela 1 apresenta descrição detalhada com os escores médios de cada indivíduo para cada fator.

Tabela 2: Escores médios e média geral dos indivíduos em relação aos fatores

\begin{tabular}{c|ccccccc}
\hline Individuo & $\begin{array}{c}\text { Aparência } \\
\text { Física }\end{array}$ & $\begin{array}{c}\text { Atitud } \\
\mathbf{e} \\
\text { Social }\end{array}$ & $\begin{array}{c}\text { Auto- } \\
\text { confiança }\end{array}$ & $\begin{array}{c}\text { Auto- } \\
\text { controle }\end{array}$ & $\begin{array}{c}\text { Receptividade } \\
\text { Social }\end{array}$ & $\begin{array}{c}\text { Regras } \\
\text { Sociais }\end{array}$ & TOTAL \\
\hline A & 3,92 & 4,80 & 5,91 & 4,23 & 4,10 & 3,75 & $\mathbf{4 , 4 5}$ \\
B & 4,61 & 2,70 & 3,66 & 3,92 & 3,73 & 4,31 & $\mathbf{3 , 8 2}$ \\
C & 4,15 & 3,70 & 3,00 & 3,46 & 3,15 & 4,43 & $\mathbf{3 , 6 5}$ \\
D & 4,23 & 2,90 & 6,16 & 3,38 & 4,10 & 3,68 & $\mathbf{4 , 0 7}$ \\
E & 4,76 & 3,70 & 4,33 & 3,76 & 4,73 & 4,00 & $\mathbf{4 , 2 1}$ \\
F & 4,07 & 3,40 & 3,75 & 3,84 & 4,15 & 3,43 & $\mathbf{3 , 7 7}$ \\
G & 4,15 & 3,30 & 4,33 & 3,30 & 4,10 & 4,00 & $\mathbf{3 , 8 6}$ \\
H & 4,00 & 4,00 & 4,91 & 3,92 & 4,00 & 3,87 & $\mathbf{4 , 1 1}$ \\
I & 4,15 & 3,80 & 3,33 & 3,92 & 4,26 & 3,93 & $\mathbf{3 , 9 0}$ \\
J & 4,00 & 3,50 & 4,08 & 4,07 & 4,21 & 3,75 & $\mathbf{3 , 9 3}$ \\
K & 4,23 & 2,70 & 4,75 & 3,15 & 4,52 & 3,81 & $\mathbf{3 , 8 6}$ \\
L & 3,84 & 4,60 & 3,75 & 3,30 & 4,21 & 4,31 & $\mathbf{4 , 0 0}$ \\
M & 4,46 & 3,50 & 4,75 & 3,76 & 4,47 & 4,18 & $\mathbf{4 , 1 9}$ \\
\hline TOTAL & $\mathbf{4 , 2 0}$ & $\mathbf{3 , 5 8}$ & $\mathbf{4 , 3 6}$ & $\mathbf{3 , 6 9}$ & $\mathbf{4 , 1 3}$ & $\mathbf{3 , 9 6}$ & $\mathbf{3 , 9 9}$ \\
\hline
\end{tabular}

O fator autoconfiança (escore 4.36) obteve o maior escore médio, seguidos pelos fatores: aparência física (escore 4.20); receptividade social (escore 4.13); regras sociais (escore 3.,96); autocontrole (escore 3.69), e o menor escore para o fator atitude social (escore 3.58), sendo que os três últimos relacionam-se com adjetivos negativos.

Analisando a dispersão das médias dos indivíduos nos fatores aparência física, autocontrole e regras sociais, conclui-se que nos três casos os indivíduos se comportam de forma regular. Já nos fatores atitude social, autoconfiança, e receptividade social, os indivíduos apresentam maior variabilidade nas médias.

\section{Discussão}

$\mathrm{O}$ autoconceito da amostra é de $3.99(\mathrm{DP}=0.21)$. Esses resultados afirmam certa homogeneidade no autoconceito da população estudada, ou seja, os lesados medulares de origem traumática, que praticam RCR e HCR há pelo menos três meses, independente do nível da lesão (tetraplegia ou paraplegia), avaliam seu autoconceito de forma semelhante. 
Tamayo et al. (2001), compararam o autoconceito de adultos sem deficiência, acima de 40 anos, praticantes e não praticantes de atividade física regular. Os escores do autoconceito global foram respectivamente 5.50 e 5.31. Assim, os resultados foram significantes para uma convergência no sentido do impacto positivo da atividade física sobre o autoconceito.

No estudo de Dalla Déa (2009), a autora analisou as alterações e correlações entre autoconceito e capacidades físicas de idosos, praticantes de atividade física no período de um ano. Os resultados mostraram melhoras significativas no autoconceito geral dos idosos após as intervenções com atividades físicas, uma vez que o escore médio no início foi de 5.33, alcançando um escore de 6.05 ao final das atividades.

Assim, ao se comparar o escore obtido neste estudo com os observados nos estudos citados acima (TAMAYO et al., 2001; DALLA DÉA, 2009), conclui-se que a amostra obteve um autoconceito global negativo, muito abaixo dos escores encontrados em outras populações praticantes de atividade física.

Tamayo (1981) cita que a mensuração do autoconceito não visa à absoluta verdade do indivíduo, mas à verdade percebida por ele mesmo. Para ele, o fundamental nessa avaliação são as percepções do indivíduo sobre si mesmo, e a maneira como elas são vivenciadas. $\mathrm{O}$ mesmo autor ainda coloca que o self é o conceito de si, desenvolvido e conservado ativamente, por meio dos mecanismos de defesa.

É importante ressaltar que essa tendência ao ponto neutro da escala pode ter sido fortemente influenciada pelos mecanismos de defesa reguladores do autoconceito. Ao se avaliar de forma neutra, sem assumir os adjetivos colocados nos extremos da escala, essa população se anula considerando-se indiferente, sem expor suas opiniões sobre si, evitando qualquer tipo de julgamento externo.

Campos, Avoglia e Custódio (2007) afirmam que a percepção de como somos vistos e avaliados pelos outro se constitui em um fator fundamental do autoconceito e do comportamento.

Mead (1963), Rodriguez Tomé (1972) e Ziller (1973) apud Tamayo (1981) enfatizam a influência da interação social na origem, estruturação e desenvolvimento do autoconceito. Fechio et al. (2009) coloca que através da interação social o indivíduo poderá descobrir novas formas de se locomover e caminhar na sociedade, reconhecendo suas 
dificuldades físicas como não impeditivas de ação social autônoma e ativa.

O esporte coletivo possui grande caráter social, proporciona a integração e o convívio com outras pessoas. Aliando esse caráter social que permeia o esporte coletivo com a influência que a atividade física exerce sobre o autoconceito (TAMAYO et al., 2001; DALLA DÉA, 2009), acredita-se na possibilidade da amostra ter apresentado um autoconceito positivo, caso fossem relacionados com um grupo de lesados medulares não praticantes de esporte adaptado. Porém, é importante ressaltar que essa é uma comparação indireta, já que as amostras variam na faixa etária, na condição física, e na delimitação da atividade física.

Dentro do fator regras sociais, a amostra se avalia de forma indiferente em relação às suas condutas e comportamentos, não se consideram completamente regulados pelas normas éticomorais, e não se reconhecem totalmente como digno e honesto.

$\mathrm{Na}$ aparência física, que envolve o self somático, os indivíduos avaliaram a percepção de seu corpo ligeiramente acima da média global. O fato de realizar uma atividade física, além de proporcionar os benefícios fisiológicos, pode ter sido determinante no efeito positivo do autoconceito dessa população, seja ele real ou apenas uma impressão.

Pode-se associar este advento ao estudo realizado por Afonso (2007), que determinou que a prática de basquetebol em cadeira de rodas interferiu positivamente no conceito de corpo de paraplégicos, criando melhor relação do indivíduo com seu corpo, não lhe provocando grande incômodo ou insatisfação, ou motivo para se esconder. No mesmo estudo, ela mostra que os paraplégicos não praticantes de atividade física possuem um conceito menos positivo, além de demonstrarem um maior retraimento quando abordados sobre esse assunto.

No presente estudo foram analisados lesados medulares de origem traumática, consequentemente usuários de cadeira de rodas. Portanto, não se pode negligenciar as relações físicas e psicológicas que esses indivíduos constroem com esse meio de locomoção. Se esta relação for bem construída, a cadeira de rodas será percebida como se fosse parte de seu corpo, substituindo os membros inferiores, causando maior satisfação corporal. Caso contrário, a cadeira é vista apenas como uma necessidade, que não faz parte de si.

Mayeda (2005) relacionou a representatividade da cadeira de rodas 
para pessoas com deficiência física, atletas e não atletas. Ela observou que no grupo de atletas a maioria considera a cadeira como parte integrante do corpo, enquanto que no grupo de não atletas, a maioria a considera apenas como um equipamento que auxilia a locomoção.

De forma indireta, pode-se associar um efeito positivo da prática esportiva na percepção da aparência física. $\mathrm{O}$ indivíduo que compreende a cadeira de rodas como uma extensão de seu corpo, reconhece sua posição de pessoa com deficiência e assume uma nova imagem de seu corpo, de forma mais positiva.

No fator autocontrole, que está inserido na dimensão do self pessoal, o escore está abaixo da média. O escore baixo para este fator indica que a amostra é no geral distraída, anárquica, sem suficiente controle do seu comportamento e sem suficiente capacidade de perceber e integrar os estímulos emitidos pelos outros e pelos objetos.

$\mathrm{Na}$ atitude social, um dos fatores da dimensão do self social, foi analisado o menor escore entre, além de grande variabilidade nas médias individuais, contemplando um intervalo de [2.70; 4.80]. O escore negativo revela que a amostra tende a um modelo de interação interpessoal brusco, agressivo e exigente.

Os indivíduos $\mathrm{B}$ e $\mathrm{K}$ tiveram a menor média, enquanto que o indivíduo A teve a maior. Ao analisar os quatro indivíduos com os menores escores para este fator (indivíduos B, D, G e K), nota-se que todos são maiores de 30 anos de idade, sendo as maiores idades da amostra, e que são os únicos com tempo de lesão igual ou acima de 10 anos. Em contrapartida, os quatro indivíduos com maior escore (indivíduos A, H, I e L), são os mais jovens da amostra, com idade entre 20 e 23 anos, e que apresentam os menores tempos de lesão (até cinco anos). Desse modo, tem-se que uma atitude social com efeito negativo pode estar relacionada com a maior idade e com o maior tempo de lesão.

A autoconfiança, que está inserida no self pessoal, apresentou o maior escore, mas é também o fator que possui maior dispersão dos escores médios dos indivíduos, variando num intervalo de [3.00; 6.16].

Ao analisar-se a citação de Tamayo et al. (2001), a qual afirma que a autoconfiança é uma exigência básica para ação e para construir uma ponte com a sociedade, nota-se que o fato de uma pessoa com deficiência procurar e se envolver em uma prática esportiva demonstra uma ação guiada por uma autoconfiança positiva.

Moreira et al. (2007) mostram em seu estudo que os fatores relaci- 
onados ao transporte e às condições financeiras são os pontos decisivos e de maiores relevâncias na interrupção da prática de atividades físicas adaptadas. Eles observam que a totalidade das 22 pessoas com deficiência motora entrevistadas na pesquisa apontou que os fatores intrínsecos, como o medo de se machucar, o medo da exclusão, a vergonha de se expor e o fato de não se sentirem bem com outras pessoas, não são motivos que os impedem de praticar a atividade esportiva adaptada. Os autores concluem afirmando que os fatores extrínsecos são os que mais influenciam os deficientes a não adesão a ou ao abandono da prática dessas atividades.

$\mathrm{Na}$ autoconfiança, o indivíduo $\mathrm{C}$ possui o menor escore médio, e o indivíduo D o maior. Ambos são paraplégicos e praticam esporte adaptado há seis meses, a informação que se mostra relevante é a diferença em relação ao tempo de lesão que há entre eles. $\mathrm{O}$ indivíduo $\mathrm{C}$ tem dois anos de lesão, é o indivíduo com menor tempo de lesão da amostra; enquanto que o indivíduo D tem dez anos de lesão. Dessa forma, comparando esses dois indivíduos, temos que o tempo de lesão pode ter sido determinante para a avaliação de uma autoconfiança positiva ou negativa.

Santana (2003) afirma que a autoconfiança é adquirida por meio de vivências positivas e de sucesso. Assim, quanto maior o tempo de lesão, maior é a probabilidade de esse indivíduo ter se adaptado a nova situação, ter passado por experiências positivas e de sucesso, e por fim, ter reconstruído sua autoconfiança de forma positiva, assumindo e compreendendo que suas limitações são meramente físicas.

A receptividade social, que pertence à dimensão do self social, concentrou-se no ponto médio da escala, com exceção do indivíduo C. Esse indivíduo apresentou um escore de 3.15 neste fator, enquanto que a média foi de 4.13. É importante considerar que, além de ser o indivíduo com menor tempo de lesão (dois anos), é também um dos quatro indivíduos que possuem menor tempo de prática esportiva. Ao comparar o indivíduo $\mathrm{C}$ com o indivíduo $\mathrm{H}$ (escore quatro para este fator), apesar de terem o mesmo tempo de lesão, ambos possuem uma diferença significativa no tempo de prática esportiva, tendo o primeiro seis meses de prática, e o segundo dois anos.

Essa diferença entre os indivíduos pode ser relacionada com o estudo de Palla (1997), no qual a autora investigou as atitudes de indivíduos com deficiência física e comparou com as atitudes dos indivíduos sem deficiência. Ela concluiu que ambos os grupos têm ati- 
tudes favoráveis em relação ao esporte. Porém, entre os indivíduos com deficiência, os efeitos positivos dependiam do tempo de prática no esporte e do grau de escolaridade. Foi sugerido que o reconhecimento cognitivo destes benefícios, embora popularmente advogados, são ignorados por conta das preocupações decorrentes das sequelas da deficiência física.

No geral, a receptividade social foi possivelmente determinada pelo tempo de prática esportiva. Assim, segundo Moreira et al. (2007) observa-se que a prática esportiva causa uma melhora significativa da socialização da pessoa com deficiência e uma motivação necessária para que participem da comunidade com mais ímpeto para produzir, trabalhar e assumir papeis de liderança.

\title{
Conclusão
}

Conclui-se que o autoconceito dos lesados medulares estudados, que praticam rúgbi e handebol em cadeira de rodas, é negativo. É importante ressaltar que a amostra foi avaliada de forma homogênea. Em relação aos fatores, foi observado que a prática de esporte adaptado revelou o maior escore para autoconfiança e para aparência física, estando estes acima da média global. Enquanto que os fatores atitude social e autocontrole apresentaram-se abaixo da média global, com os menores escores. Porém, todos eles foram considerados negativos.

\section{Assessing self-concept for wheel chair users practicing disabled sports}

\begin{abstract}
In this study, we aimed at assessing self-concept by using its aspects (somatic, personal, social, ethical-moral) for wheelchair users who practise disabled sports. The tool used was the Self-Concept Scale Factor (sCSF), proposed for Tamayo (1981). We collected data only once from 13 volunteers, aged 28.46 years, with SCI (regardless of gender), and from volunteers practising disabled sports for at least two hours weekly within at least three months. The results showed the global self-concept with a score of 3.99. We conclude that the population assesses their self-concept negatively, compared to previous studies to other populations.
\end{abstract}

Keywords: Self-Concept with Physical Disabilities - SCI - Disabled Sports

La evaluación del autoconcepto em silla de ruedas qué práticam deportes adptado

\section{Resumen}

Este estudio tuvo como objetivo evaluar el concepto de sí mismo, por sus dimensi- 
ones (somático, personal, social y ético-moral), de silla de ruedas que practican deportes adaptado. El instrumento utilizado fue la Escala Fatorial do Autoconceito (EFA), propuesta por Tamayo (1981). Se recogieron datos de 13 voluntarios con una edad de 28,46 años ( $\mathrm{SD}=5.93)$, las lesiones medulares de origen traumático, sin importar el sexo, la práctica de deportes adaptados para al menos dos horas semanales durante al menos 3 meses. Los resultados mostraron el concepto de sí mismo de la población fue negativo, con una puntuación de 3,99. Estos resultados indican que las personas con lesion de la médula espinal de origen traumático que prácticam deportes adaptados evaluar su autoconcepto negativo.

Palabras clave: Autoconceito - Persona com Discapacidad - Lesión de Médula Espinal - Deportes Adaptado

\section{Referências}

AFONSO, L. A. O deficiente motor: actividade física, conceito de corpo e imagem corporal - um estudo em praticantes e não praticantes de basquetebol em cadeira de rodas. 2007. 133 f. Dissertação (Mestrado) - Departamento de Faculdade de Desporto, Universidade do Porto: Porto, 2007.

BRAZUNA, M. R.; MAUERBERG-DECASTRO, E. A Trajetória do Atleta Portador de Deficiência Física no Esporte Adaptado de Rendimento: Uma Revisão da Literatura. Motriz, Rio Claro, v. 7, n. 2, p.115-123, jul. 2001. Disponível em: <http://www.rc.unesp.br/ib/efisica/motriz/07n2/Brazuna.pdf>. Acesso em: 15 set. 2009.

CAMPOS, M. T.; AVOGLIA, H. R. C.; CUSTÓDIO, E. M. A imagem corporal de indivíduos com paraplegia não congênita: um estudo exploratório. Psicólogo Informação, São Paulo, v. 11, n. 11, p.27-55, 01 jan. 2007. Disponível em: <https://www.metodista.br/revistas/revistasmetodista/index.php/PINFOR/article/viewFile/531/529>. Acesso em: 12 set. 2009.

DALLA DÉA, V. H. S. Autoconceito e capacidades físicas de idosos depressivos e não depressivos participantes de um programa de atividade física de longa duração. 2009. 263 f. Tese (Doutorado) Departamento de Faculdade de Educação Física, Universidade Estadual de Campinas, Campinas, 2009.

DALLA DÉA, V. H. S.; DUARTE, E. Síndrome de down: informações, caminhos e histórias de amor. São Paulo: Phorte, 2009. p. 83-89. 
GORLA, J. I.; CAMPANA, M. B.; OLIVEIRA, L. Z. Teste e avaliação em esporte adaptado. São Paulo: Phorte, 2009. Cap. 1, p. 23-37.

INSTITUTO Brasileiro de Geografia e Estatística (IBGE). Censo Demográfico 2000. Disponível em: http://www.ibge.gov.br/home/estatistica/populacao/censo2000/default.shtm. Acesso em: 28 set. 2009.

MANHÃES, R. B. A engenharia de reabilitação e as características psicossociais de pessoas com lesão medular submetidas a um programa de estimulação elétrica neuromuscular. 2004. 248 f. Dissertação (Mestrado) - Departamento de Bioengenharia, Universidade de São Paulo, São Carlos, 2004. Disponível em: <http://www.teses.usp.br/teses/disponiveis/82/82131/tde-28102004-100130/>. Acesso em: 10 ago. 2009.

MAYEDA, S. Minha cadeira de rodas, meu corpo: as diferenças percepções corporais dos usuários. 2005. $58 \mathrm{f}$. Monografia (Especialização) - Universidade Estadual de Campinas, Campinas, 2005.

MOREIRA, W. C.; RABELO, R. J.; DE PAULA, A. H.; COTTA, D. $O$. Fatores que influenciam a adesão de deficientes motores e deficientes visuais a pratica desportiva. Ef Deportes, Buenos Aires, n. , p.1-1, 01 jan. 2007. Disponível em: <http://www.efdeportes.com/efd104/deficientes-motores-visuais.htm>. Acesso em: 12 set. 2009.

PALLA, A.C. Atitudes em relação ao esporte: estudo comparativo entre atletas portadores de deficiências físicas e atletas não portadores de deficiências. 46 p. Monografia (Graduação) - Universidade Estadual Paulista, Rio Claro, 1997.

SANTANA, V. H. Avaliação do autoconceito e a atividade física. 2003. 116 f. Dissertação (Mestrado)-Faculdade de Educação Física, Universidade Estadual de Campinas, Campinas, 2003.

TAMAYO, A.; CAMPOS, A. P. M.; MATOS, D. R.; MENDES, G. R.; SANTOS, J. B.; CARVALHO, N. T. A influência da atividade física regular no autoconceito. Estudos de Psicologia, 6(2): 157-165, out, 2001.

TAMAYO, A. EFA: escala fatorial do autoconceito. Arquivo Brasileiro de Psicologia, Rio de Janeiro, 33(4): 87-102, out/dez, 1981. 
THOMAS, J. R.; NELSON, J. K. Métodos de pesquisa em atividade física. Porto Alegre: Artmed, 2002.

WINNICK, J. P. Educação física e esportes adaptados. Barueri, SP: Manole, 2004.

ZUGLIANI, A. P.; MOTTI, T. F. G.; CASTANHO, R. M. O autoconceito do adolescente deficiente auditivo e sua relação com o uso do aparelho de amplificação sonora individual. Revista Brasileira de Educação Especial. 2007, vol.13, n.1, pp. 95-110. Disponível em: $<$ http://www.scielo.br/scielo.php?pid=S1413-

$65382007000100007 \&$ script $=$ sci_arttext\&tlng $=\mathrm{g}>$. Acesso em: 05 jun. 2009.

Recebido em: 23/06/2010

Revisado em: 20/09/2010

Aprovado em: 04/10/2010

\section{Endereço para correspondência}

vanessasantana@ig.com.br

Vanessa Helena Santana Dalla Déa

Universidade Federal de Goiás

Faculdade de Educação Física

Câmpus Samambaia (Câmpus II)

Caixa Postal: 131

CEP:74001-970 - Goiânia - GO - Brasil 